\title{
Impressions from EASD 2017
}

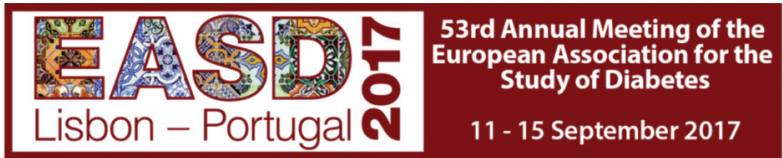

\author{
Dr Caroline Day reports from the European Association for the Study of Diabetes \\ 53rd Annual Meeting in Lisbon, Portugal, 11th-15th, September 2017
}

\begin{abstract}
Introduction
The Lisbon International Fair, Parque das Nacoes, located near the bank of the tidal Targus with views of the impressive Vasco da Gama bridge to one side and easy access to shopping malls and underground and mainline railway stations to the other, was the 2017 venue for the 53rd annual EASD meeting. The 47th Annual EASD meeting was held here in 2011, but this year there were fewer delegates $(n=15,436)$ than in $2011(n=17,462)$, although numbers were consistent with last year's EASD attendance $(n=15,318)$. As in 2016, the UK retained second position - again behind Germany amongst the 130 countries represented at this year's meeting.
\end{abstract}

\begin{abstract}
s
This year abstracts 1-264 were presented in 48 oral sessions and abstracts 265-1266 were presented across six poster events. Abstracts could be viewed singly via the conference website (with the facility for individual on-site printout), but Diabetologia also produced a virtual supplement (ISSN 0012-186X will lead to the printed publication) - thus the potential for serendipity lingers. 1,2 Perusal of the outline programme may accelerate navigation of the virtual meeting, especially when seeking the noncommercial and scientific sessions symposia, or view the final programme which is available as a pdf (summary programme, pages 30-33). 3,4
\end{abstract}

\section{From metformin to ...}

Again this year the prize lectures (Table 1) were diverse, providing enlightening background and state-of-the-art information as well as some interesting personal asides check out the virtual meeting and EASD interviews on YouTube.

2017 marked the 60th anniversary year of the first clinical use of the biguanide metformin to treat diabetes. A special issue of Diabetologia was devoted to metformin and distributed in real-world printed/physical form (Figure 1). ${ }^{5}$ There was an EASD Diamond symposium session and an industry (Merck KgA) sponsored symposium with

Table 1 Prize lectures at EASD 2017

\begin{tabular}{|c|c|c|}
\hline Prize & Lecturer & $\begin{array}{l}\text { Title (day of presentation) and link to } \\
\text { EASD interview }\end{array}$ \\
\hline $\begin{array}{l}\text { Claude } \\
\text { Bernard } \\
\text { Lecture }\end{array}$ & $\begin{array}{l}\text { Bernard Thorens } \\
\text { (Lausanne, } \\
\text { Switzerland) }\end{array}$ & $\begin{array}{l}\text { A glucose-centric view on diabetes } \\
\text { pathogenesis: from islet biology to } \\
\text { integrated physiology and precision } \\
\text { medicine (Tuesday) } \\
\text { https://www.youtube.com/watch?v=iYKWa4cKZX8 }\end{array}$ \\
\hline $\begin{array}{l}\text { Camillo } \\
\text { Golgi } \\
\text { Lecture }\end{array}$ & $\begin{array}{l}\text { Brian M Frier } \\
\text { (Edinburgh, UK) }\end{array}$ & $\begin{array}{l}\text { Recurrent hypoglycaemia in diabetes: the long-term } \\
\text { complications (Tuesday) } \\
\text { https://www.youtube.com/watch?v=wAUJ5bHvN4c }\end{array}$ \\
\hline $\begin{array}{l}\text { Albert } \\
\text { Renold } \\
\text { Lecture }\end{array}$ & $\begin{array}{l}\text { Jorge Ferrer } \\
\text { (London, UK) }\end{array}$ & DNA switches; beta cells and diabetes (Tuesday) \\
\hline $\begin{array}{l}\text { EASD-Novo } \\
\text { Nordisk } \\
\text { Foundation } \\
\text { Diabetes } \\
\text { Prize for } \\
\text { Excellence }\end{array}$ & $\begin{array}{l}\text { Philip E Sherer } \\
\text { (Dallas, USA) }\end{array}$ & $\begin{array}{l}\text { The many secret lives of adipocytes: implications for } \\
\text { diabetes (Wednesday) } \\
\text { https://www.youtube.com/watch?v=XG8cih6J-7A }\end{array}$ \\
\hline $\begin{array}{l}\text { Minkowski } \\
\text { Lecture }\end{array}$ & $\begin{array}{l}\text { Ewan Pearson } \\
\text { (Dundee, UK) }\end{array}$ & $\begin{array}{l}\text { Targeting therapy in diabetes: insights from } \\
\text { genetics (Thursday) } \\
\text { https://www.youtube.com/watch?v=S0ycfWpb6U4 }\end{array}$ \\
\hline
\end{tabular}

Figure 1. Diabetologia: metformin special issue, 2017

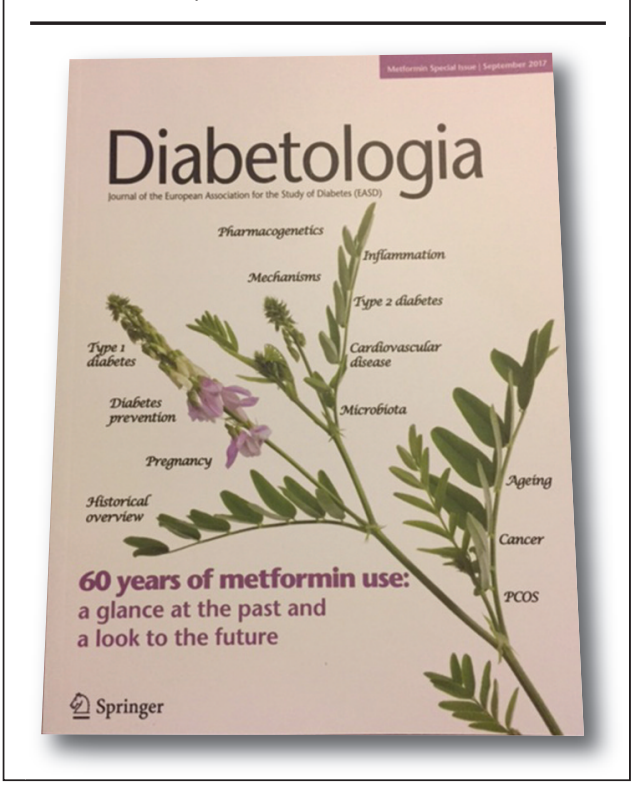

accompanying book - however, if you want a comprehensive but detailed grounding in metformin, seek out the text compiled to celebrate 50 years of metformin.6,7 For a rapid metformin resume from herbal remedy to pharmaceutical glucose-lowering drug (Glucophage ${ }^{\circledR}$ ) - its emergence from the shadow of the sulphonylureas to becoming the world's most prescribed drug for diabetes - it is worth watching the EASD metformin interview. $^{8}$

Metformin in established type 1 diabetes, investigated in the REMOVAL study, was the subject of a Sunday afternoon pre-meeting EASD symposium. Data presented at ADA showed benefits of metformin treatment in these patients, including improved eGFR $(p<0.0001)$, and the EASD session discussed new post hoc analyses which confirmed the original observation and suggest that improved eGFR is due to a direct effect of metformin on the kidney. ${ }^{9,10}$ 
Cardiovascular outcome trials in type 2 diabetes

No differences in cardiovascular outcomes were observed when comparing pioglitazone versus a sulphonylurea (gliclazide 50\%, glimepiride $48 \%$, glibenclamide $2 \%$ ) as addon to metformin for a median 4.8 years in TOSCA.IT. ${ }^{11}$ In EXSCEL, treatment of type 2 diabetes patients (of whom 73\% had prior cardiovascular disease) with exenatide once weekly for a median of 3.2 years was noninferior to usual care (HR $0.91(0.83,1.00)$, $p<0.001)$ for the primary outcome of 3-point MACE (composite of cardiovascular death or non-fatal myocardial infarction or non-fatal stroke), although there was a 14\% $(p<0.016)$ risk reduction in all-cause mortality. ${ }^{12,13}$ DEVOTE noted the similarity of the basal insulins degludec and glargine on cardiac safety (3-point MACE) in type 2 diabetes and lower rates of hypoglycaemia with degludec compared to glargine. ${ }^{14,15}$ The results of the CANVAS programme were reiterated (treatment with canagliflozin significantly reduced cardiovascular risk (3-point MACE) compared to usual risk). ${ }^{16}$ However, there was an unexpected increase in amputations in canagliflozin-treated patients $(p<0.001)$, and this prompted a re-examination of amputations in EMPA-REG. There were 6.3 amputations/1000 patient years in both the canagliflozin-treated and empagliflozintreated groups, as well as the EMPA-REG placebo group. However, there were only 3.4 amputations/1000 patient years in the CANVAS placebo group. ${ }^{17}$

\section{Cardiovascular disease and diabetes prevention}

The ACE study was conducted to establish if acarbose added to usual cardiovascular care could reduce the incidence of cardiovascular events and type 2 diabetes in patients with coronary heart disease and impaired glucose tolerance. The study was conducted in China where almost $50 \%$ of adults have pre-diabetes. Patients $(n=6,522)$ were randomised $1: 1$ and followed for a median of 5 years. Treatment with acarbose $(50 \mathrm{mg}$ three times daily) did not reduce the risk of major adverse cardiovascular events but did reduce the incidence of type 2 diabetes (13\% vs. $16 \%$, rate ratio $\mathrm{p}=0.005) .{ }^{18,19}$

Cardiovascular risk and PCSK9 inhibitors The injectable PCSK9 inhibitors have shown LDL lowering efficacy that is additional to that achieved by statins. The alirocumab ODYSSEY-DM studies (INSULIN and DYSLIPIDEMIA), originally reported at ADA, showed improvement (versus usual care) in type 2

\begin{tabular}{ll} 
ACE & Acarbose Cardiovascular Evaluation \\
\hline CANVAS & CANagliflozin and cardioVascular Assessment Study \\
\hline DEVOTE & $\begin{array}{l}\text { A trial comparing cardiovascular safety of insulin Degludec versus } \\
\text { insulin Glargine in subjects with type } 2 \text { diabetes at high risk of } \\
\text { cardiovascular events }\end{array}$ \\
\hline DEPICT & $\begin{array}{l}\text { Dapagliflozin Evaluation in Patients With Inadequately Controlled } \\
\text { Type 1 diabetes }\end{array}$ \\
\hline EMPA-REG OUTCOME & $\begin{array}{l}\text { Empagliflozin cardiovascular Outcome event trial in type 2 dia- } \\
\text { betes mellitus patients }\end{array}$ \\
\hline EXSCEL & EXenatide Study of Cardiovascular Event Lowering \\
\hline FOURIER & $\begin{array}{l}\text { Further cardiovascular OUtcomes Research with PCSK9 Inhibition } \\
\text { in subjects with Elevated Risk }\end{array}$ \\
\hline J-DOIT3 & $\begin{array}{l}\text { Japan-Diabetes Optimisation Integrated Treatment study for } \mathbf{3} \\
\text { major risk factors of cardiovascular diseases }\end{array}$ \\
\hline ODYSSEY DM-Dyslipidemia & $\begin{array}{l}\text { Efficacy and safety of Alirocumab versus usual care on top of } \\
\text { maximally tolerated statin therapy in patients with type } 2 \text { Diabetes } \\
\text { Mellitus and mixed Dyslipidemia }\end{array}$ \\
\hline inTANDEM & $\begin{array}{l}\text { Efficacy and safety of Alirocumab versus placebo on top of } \\
\text { maximally tolerated lipid lowering therapy in patients with } \\
\text { hypercholesterolemia who have type 1 or type 2 Diabetes Mellitus } \\
\text { and are treated with Insulin }\end{array}$ \\
\hline ODYSSEY DM-Insulin & $\begin{array}{l}\text { REducing with MetfOrmin Vascular Adverse Lesions in type 1 } \\
\text { diabetes }\end{array}$ \\
\hline $\begin{array}{l}\text { Sotagliflozin plus insulin in type 1 diabetes } \\
\text { Thiazolidinediones Or Sulfonylureas Cardiovascular Accidents } \\
\text { Intervention Trial }\end{array}$ \\
\hline
\end{tabular}

diabetes patients with mixed dyslipidaemia and in hypercholesterolaemic insulin-treated patients with type 1 and type 2 diabetes. Presentations at EASD contained further data regarding alirocumab use in patients with type 1 diabetes. ${ }^{20,21}$ The FOURIER study also showed that evolocumab reduced cardiovascular risk in patients with diabetes and in patients without diabetes. Evolocumab did not worsen glycaemic control and did not increase the risk of diabetes. ${ }^{22,23}$

\section{Cardiovascular risk and intensive management}

In the J-DOIT3 study, type 2 diabetes patients $(n=2,542)$ with hypertension or dyslipidaemia were assigned 1:1 to usual care or intensive treatment of glucose, lipid and blood pressure and followed up for 8.5 years. Intensive multifactorial control - targeting normal or near-normal values - reduced the risk of microvascular and macrovascular complications. ${ }^{24}$

\section{... newer agents}

The SGLT2 inhibitors are the most recent class of agent to join the glucose-lowering armamentarium. Sessions devoted to the use of this class of agents in the treatment of type 1 diabetes focused on the DEPICT and inTANDEM studies. DEPICT showed that addition of dapagliflozin $(5 \mathrm{mg}$ or $10 \mathrm{mg}$ ) for 24 weeks reduced $\mathrm{HbA}_{1 \mathrm{c}}$ (both $p<0.0001)$. The incidence of hypoglycaemia was similar in dapagliflozin-treated and placebo groups and diabetic ketoacidosis occurred in 1\%, $2 \%$ and $1 \%$ of patients in the dapagliflozin $5 \mathrm{mg}, 10 \mathrm{mg}$ and placebo groups, respectively. ${ }^{25,26}$ Sotagliflozin is in phase 3 development, and this agent has notable SGLT1 and well as SGLT2 inhibitory activity. In the inTANDEM study, addition of sotagliflozin $(400 \mathrm{mg}$ ) for 24 weeks reduced $\mathrm{HbA}_{1 c}(p<0.0001)$; the incidence of severe hypoglycaemia was similar in the treated $(3 \%)$ and placebo (2.4\%) groups and diabetic ketoacidosis occurred in $3 \%$ of patients receiving sotagliflozin and $0.4 \%$ of patients in the placebo group. ${ }^{27,28}$

\section{Anything else?}

The role of advocacy in advancing care for people with diabetes was evident with the introduction of the International Diabetes 
Federation (IDF) Europe IMPACT (Initiative to Mobilise Parliamentariums to Act to Prevent, Care and Treat diabetes) programme which endeavours to build a pan-European forum to drive positive change in diabetes care. Might we expect a reincarnation of the St Vincent Declaration? The Parliamentarians for Diabetes Global Network (PGDN) - remember the Melbourne Declaration (2013) and Vancouver Proclamation (2015) - has been instrumental in helping people hold their governments to account regarding issues relating to health and diabetes care. Their next forum will be in the European Capital of Culture, Valetta, Malta in 2018.

The Messe Berlin (aka Berlin ExpoCenter City), Messedamm 22, will host EASD 2018. As in 2012, when EASD last visited Berlin, the EASD will be held later than usual on 2 nd -5 th October.

\section{References}

1. Virtual meeting (abstracts, posters, webcasts). EASD, 2017. https://www.easd.org/virtualmeeting/home. html\#!resourcegroups/resourcetype_ids=1\&event_ids $=12$

2. Abstracts of the 53rd EASD Annual Meeting, Lisbon, Portugal, 11-15 September 2017. Diabetologia 2017;60(Suppl 1):1-608. https://doi.org/10.1007/s00125-017-4350-z

3. EASD. Programme at a glance, 2017. https://www.easd.org/programme-glance.htm

4. EASD. Final Programme of the 53rd EASD Annual Meeting, 2017. https://www.easd.org/sites/default/ files/EASD_2017_Final\%20Programme.pdf

5. 60 years of metformin use: a glance at the past and a look to the future. Diabetologia Special Issue, September 2017, 107pp. http://www.diabetologiajournal.org/webpages/metformin.html

6. Campbell IW, Howlett HCS, Holman RR, Bailey CJ, eds. Metformin. 60 years of clinical experience. (Addendum to the Scientific Handbook). Weinheim, Germany: Wiley-VCH, 2017:122pp. ISBN 978-3-52734449-9.

7. Bailey CJ, Campbell IW, Chan JCN, et al, eds. Metformin. The gold standard. (A Scientific Handbook). Chichester, UK: John Wiley \& Sons, 2007:288pp. ISBN 987-0-470-72542-9).

8. Bailey C, Marshall S. Diabetes and metformin. EASD, 2017.
https://www.youtube.com/watch?v=S073z7aJyhw

9. Petrie JR, Chatuverdi N, Ford I, et al, for the REMOVAL Study Group. Cardiovascular and metabolic effects of metformin in patients with type 1 diabetes (REMOVAL): a double-blind, randomised, placebocontrolled trial. Lancet 2017:5:597-609. http://dx.doi.org/10.1016/S2213-8587(17)30194-8

10. REMOVAL: a randomized controlled trial of metformin in adults with type 1 diabetes. EASD, 2017. https://www.easd.org/removal.html

11. Vaccaro O, Masulli M, Nicolucci A, et al, for the Thiazolidinediones Or Sulfonylureas Cardiovascular Accidents Intervention Trial (TOSCA.T) Study Group. Effects on the incidence of cardiovascular events of the addition of pioglitazone versus sulfonylureas in patients with type 2 diabetes inadequately controlled with metformin (TOSCA.IT): a randomised, multicentre trial. Lancet Diabetes Endocrinol 2017;5:887-97. http://dx.doi.org/10.1016/52213-8587(17)30317-0

12. EXenatide Study of Cardiovascular Event Lowering (EXSCEL): primary results. EASD, 2017. https://www. easd.org/virtualmeeting/home.html\#! contentsessions $/ 2628$

13. Holman RR, Bethel MA, Mentz RJ, Thompson VP, et al. Effects of once-weekly exenatide on cardiovascular outcomes in type 2 diabetes. N Engl J Med 2017:377 1228-39. http://dx.doi.org/10.1056/NEJMoa1612917

14. Insulin degludec vs glargine: cardiovascular safety in type 2 diabetes: the DEVOTE study. EASD, 2017. https://www.easd.org/virtualmeeting/home.html\#!co ntentsessions/2613

15. Marso SP, McGuire DK, Zinman B, et al, for the DEVOTE Study Group. Efficacy and safety of degludec versus glargine in type 2 diabetes. $N$ Engl J Med 2017:377:723-32. http://dx.doi.org/10.1056/NEJMoa1615692

16. Neal B, Perkovic V, Mahaffey KW, et al, for the CANVAS Program Collaborative Group. Canagliflozin and cardiovascular and renal events in type 2 diabetes. N Engl J Med 2017:377:644-57. http://dx.doi.org/10.1056/NEJMoa1611925

17. CANagliflozin cardioVascular Assessment Study (CANVAS). EASD, 2017 (for amputations see Radholm $\mathrm{K}$ et al submitted- reported at EASD, 2017) https://nww. easd.org/virtualmeeting/home.html\#!resources/canaglifl ozin-cardiovascular-assessment-study-canvas

18. Acarbose Cardiovascular Evaluation (ACE): primary results. EASD, 2017. https://www.easd.org/virtualmeeting/home.html\#! contentsessions/2631

19. Holman RR, Colemena RL, Chan JCN, et al. Effects of acarbose on cardiovascular and diabetes outcomes in patients with coronary heart disease and impaired glucose tolerance (ACE): a randomised, double-blind, placebo-controlled trial. Lancet Diabetes Endocrinol 2017:5:877-86.

http://dx.doi.org/10.1016/\$2213-8587(17)30309-1
20. Role of alirocumab in lipid management of individuals with type 1 and type 2 diabetes at high CV risk: ODYSSEY DM program. EASD, 2017. https://www. easd.org/virtualmeeting/home.html\#! contentsessions/2600

21. Leiter LA, Cariou B, Muller-Wieland D, et al. Efficacy and safety of alirocumab in insulin-treated individuals with type 1 or type 2 diabetes and high cardiovascular risk: The ODYSSEY DM-INSULIN randomized trial. Diabetes Obes Metab 2017;19:1781-92. http://dx.doi.org/10.1111/dom.13114

22. Evolocumab in diabetes and diabetes risk: novelties from the FOURIER study. EASD, 2017. https://www. easd.org/virtualmeeting/home.html\#! contentsessions/2619

23. Sabatine MS, Leiter LA, Wiviott SD, et al. Cardiovascular safety and efficacy of the PCSK9 inhibitor evolocumab in patients with and without diabetes and the effect of evolocumab on glycaemia and risk of new onset diabetes: a prespecified analysis of the FOURIER randomised controlled trial. Lancet Diabetes Endocrinol 14 September 2017 [Epub ahead of print] 10.1016/\$2213-8587(17)30313-3.

24. J-DOIT3: a multifactorial intervention trial for prevention of macrovascular complications and mortality. EASD, 2017. https://www.easd.org/virtualmeeting/ home.html\#! contentsessions/2621

25. SGLT2 inhibitors: novel therapies for type 1 diabetes. EASD, 2017. https://www.easd.org/virtualmeeting/ home.html\#! contentsessions/2606

26. Dandona $\mathrm{P}$, Mathieu C, Phillip M, et al. Efficacy and safety of dapagliflozin in patients with inadequately controlled type 1 diabetes (DEPICT-1): 24 week results from a multicentre, double-blind, phase 3 randomised controlled trial. Lancet Diabetes Endocrinol 2017:5 864-76. http://dx.doi.org/10.1016/\$2213-8587(17)30308

27. An emerging and innovative therapeutic approach in type 1 diabetes with dual SGLT1 and SGLT2 inhibition: the Sotagliflozin Clinical Program. EASD, 2017. https://www.easd.org/virtualmeeting/home.html\#!co ntentsessions/2587

28. Garg SK, Henry RR, Banks P, et al. Effects of sotagliflozin added to insulin in patients with type 1 diabetes. N Engl J Med 13 September 2017 [Epub ahead of print]. 10.1056/NEJMoa1708337

Correspondence: Dr Caroline Day Visiting Fellow, Diabetes Group, Aston University, Birmingham B4 7ET, UK Email: cday@mededuk.com

https://doi.org/10.15277/bjd.2017.154 Br J Diabetes 2017;17:167-169 